Research Paper

\title{
Emulsified Isoflurane Preconditioning Protects Isolated Rat Kupffer Cells against Hypoxia/Reoxygenation- Induced Injury
}

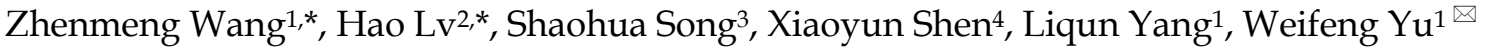 \\ 1. Department of Anaesthesia and Intensive Care, Eastern Hepatobiliary Surgery Hospital, Second Military Medical University, Shanghai, \\ 200438, China. \\ 2. Department of Anaesthesia, Navy General Hospital of People's Liberation Army, 6\# Fucheng Road, Beijing, 100048, China. \\ 3. Organ Transplantation Center, Changzheng Hospital, Second Military Medical University, Shanghai, 200002, China. \\ 4. Department of Experiment Study, Affiliated Tumor Hospital of Guangxi Medical University, Nanning, Guangxi Autonomous Region, \\ 530021, China. \\ * These authors contributed equally to this work.
}

$\triangle$ Corresponding author: Wei-Feng Yu, M.D, Department of Anesthesia and Intensive Care, Eastern Hepatobiliary Surgery Hospital, Second Military Medical University, 225\# Changhai Road, Shanghai, 200438, China, Phone and Fax: +862181875231. E-mail address: ywf808@sohu.com.

() Ivyspring International Publisher. This is an open-access article distributed under the terms of the Creative Commons License (http://creativecommons.org/ licenses/by-nc-nd/3.0/). Reproduction is permitted for personal, noncommercial use, provided that the article is in whole, unmodified, and properly cited.

Received: 2012.10.05; Accepted: 2013.01.15; Published: 2013.01.26

\begin{abstract}
Objective: To investigate the protective effect of emulsified isoflurane (El) preconditioning on isolated rat Kupffer cells (KCs) subjected to hypoxia/reoxygenation (H/R)-induced injury.

Materials and methods: KCs were isolated by collagenase digestion and purified by Percoll density gradient centrifugation. Primary cultured KCs were divided into five groups: control, $H / R$ plus $0.1 \%$ lipid preconditioning, and $\mathrm{H} / \mathrm{R}$ plus $0.05 \%, 0.1 \%$ or $0.2 \%$ emulsified isoflurane preconditioning groups. $\mathrm{H} / \mathrm{R}$ was induced by $4 \mathrm{~h}$ of hypoxia followed by $6 \mathrm{~h}$ of reoxygenation. Reactive oxygen species (ROS) production in the KCs and the concentration of tumor necrosis factor- $\alpha$ (TNF- $\alpha$ ) in the KC culture media were measured, and the apoptosis of KCs was assayed concomitantly.

Results: ROS and TNF- $\alpha$ production were markedly induced in the H/R + lipid group, and lower in the $0.2 \%$ and $0.1 \%$ El groups $(P<0.05)$. The apoptotic rate in the $H / R+$ lipid group was significantly higher than that in the $0.2 \%$ and $0.1 \%$ El groups $(P<0.05)$.

Conclusions: Emulsified isoflurane protects isolated rat $K C s$ against $H / R$ induced injury by decreasing the production of ROS and TNF- $\alpha$ and attenuating apoptosis in KCs.
\end{abstract}

Key words: kupffer cells; emulsified isoflurane; oxidative stress; rats; apoptosis.

\section{Introduction}

Various methods, including pharmacological treatment, gene therapy and ischemic preconditioning, have been used to ameliorate hepatic ischemia/reperfusion (I/R) injury. In 1986, Murry et $\mathrm{al}^{1}$ demonstrated for the first time that intermittent episodes of ischemia had a protective effect on myocar- dium that was later subjected to a sustained bout of ischemia. One of the characteristics of ischemic preconditioning is the cross-tolerance phenomenon. In 1997, some experimental studies $^{2}$ confirmed that isoflurane preconditioning could reduce myocardial infarct size in a dog model of left anterior descending 
coronary artery occlusion. Isoflurane has also been shown to reduce oxidative stress-induced cell injury.

Kupffer cells (KCs), which are liver-specific tissue-fixed macrophages and a major component of the reticuloendothelial system, phagocytose foreign bodies and produce or secrete various physiological signaling factors, such as reactive oxygen species (ROS), proinflammatory cytokines, chemokines and other mediators, to regulate systemic responses during major stress or sepsis ${ }^{3,4}$. KCs are activated under I/R stress and are considered to play an important role in I/R injury 5 .

In this study, we examined the effect of emulsified isoflurane preconditioning on the hypox$\mathrm{ia} /$ reoxygenation induced apoptosis of KCs and on the production of ROS and TNF-a by KCs to determine whether the cell injury may be ameliorated by emulsified isoflurane treatment.

\section{Materials and methods}

\section{Animals}

Inbred male Sprague-Dawley (SD) rats weighing 200-250 g (Experimental Animal Center of the Second Military Medical University, Shanghai, China) were maintained in laminar flow cages in a specific pathogen free animal facility with free access to standard laboratory chow and water before the experiment. This study was approved by the animal care committee at the Second Military Medical University and all experimental procedures were performed according to the Guide for the Care and Use of Laboratory Animals.

\section{Preparation of emulsified isoflurane}

An $8 \%$ emulsified isoflurane $(\mathrm{v} / \mathrm{v})$ solution was manufactured by Huarui Pharmacy (Wuxi, China) according to previously described procedures 6,7 and kindly provided by Prof. Jin Liu from the Laboratory of Anesthesiology and Critical Care Medicine, West China Hospital of Sichuan University (Chengdu, China). Briefly, $1.6 \mathrm{~mL}$ liquid isoflurane and $18.4 \mathrm{~mL}$ $30 \%$ Intralipid ${ }^{\circledR}$ (fat emulsion injection, Sino-Swed Pharmaceutical Corp., China) were mixed in a $20-\mathrm{mL}$ glass ampoule, which was sealed using an alcohol blowtorch. The ampoule was then shaken vigorously on a vibrator for $15 \mathrm{~min}$ to solubilize the isoflurane as a lipid emulsion. The emulsified isoflurane ampoule was opened just before use, and any residual drug was discarded. Before the experiment, the stability of $8 \%$ emulsified isoflurane was verified by gas chromatography. There was no change in isoflurane concentration or generation of lipid droplets over 6 months of storage at room temperature.

\section{Isolation and culture of $\mathrm{KCs}$}

KCs were isolated by collagenase digestion ${ }^{8}$ and purified by Percoll density gradient centrifugation ${ }^{9}$. Rats were anesthetized with $50 \mathrm{mg} / \mathrm{kg}$ pentobarbital intraperitoneally prior to laparotomy. The portal vein was cannulated with a $22 \mathrm{G}$ catheter, and the liver was perfused in situ with $200 \mathrm{ml} \mathrm{Ca}{ }^{2+} / \mathrm{Mg}^{2+}$-free Hanks' balanced salt solution (HBSS) containing $10 \mathrm{mM}$ 4-(2-hydroxyethyl)-1-piperazine ethanesulfonic acid at $37^{\circ} \mathrm{C}$ and $20 \mathrm{ml} / \mathrm{min}$ in a non-recirculating fashion. The liver was then excised and transferred to a $35 \mathrm{~mm}$ culture dish, and perfusion was continued ex situ with $50 \mathrm{ml}$ HBSS containing $0.05 \%$ IV collagenase and $5 \mathrm{mM}$ 4-(2-hydroxyethyl)-1-piperazine ethanesulfonic acid at $37^{\circ} \mathrm{C}$ and $20 \mathrm{ml} / \mathrm{min}$ in a recirculating fashion for $20 \mathrm{~min}$. After perfusion, the liver was placed in a culture dish, and non-parenchymal cells (NPCs) and parenchymal cells were isolated from the connective tissue by carefully mincing and gently shaking the liver. The liver homogenate was then filtered through a $70 \mu \mathrm{m}$ nylon mesh to remove undigested tissue. The cell suspension was centrifuged at $50 \mathrm{~g}$ for $5 \mathrm{~min}$ three times at $4^{\circ} \mathrm{C}$. The supernatant was centrifuged at $800 \mathrm{~g}$ for $10 \mathrm{~min}$ to obtain hepatic NPCs. The pelleted cells were re-suspended in HBSS and centrifuged at $800 \mathrm{~g}$ for $15 \mathrm{~min}$ through a $25 \% / 50 \%$ Percoll gradient at $4^{\circ} \mathrm{C}$.

The interface of the gradient containing KCs was re-suspended in RPMI-1640 containing 10\% fetal bovine serum (FBS), penicillin and streptomycin. Cells were then plated in 24- and 6-well culture plates at $1 \times 10^{6} /$ well and $2 \times 10^{6} /$ well, respectively. KCs were cultured in an incubator under a humidified atmosphere of $5 \% \mathrm{CO}_{2}$ at $37^{\circ} \mathrm{C}$ for $3 \mathrm{~h}$ and then washed with PBS. Adherent cells were cultured in an incubator at $37^{\circ} \mathrm{C}$ with $5 \% \mathrm{CO}_{2}$ for $24 \mathrm{~h}$ for later study. The identity of the KCs was confirmed by endogenous peroxidase activity as evaluated by diaminobenziding staining ${ }^{10}$, which produces a yellow staining and a typical 'fried egg' appearance in $\mathrm{KC}$ cells ${ }^{11}$. The purity of the isolated KCs was more than $85 \%$, and the viability was more than $95 \%$, as measured by the Trypan blue exclusion test.

\section{Emulsified isoflurane preconditioning and hy- poxia/reoxygenation}

10 rats were sacrificed and the KCs were harvested separately. KCs from each rat were cultured and divided into the control, lipid, $0.05 \%, 0.1 \%$ and $0.2 \%$ group. The KCs of the control and lipid group were preconditioned with the same vender for making emulsified solution, and $\mathrm{KCs}$ of the emulsified isoflurane group were preconditioned with a final concentration of $0.05 \%, 0.1 \%$ or $0.2 \%$ emulsified isoflurane for $0.5 \mathrm{~h}$ and then placed in a plexiglass 
chamber. The chamber was closed tightly and purged continuously with humidified $90 \% \mathrm{~N}_{2} / 10 \% \mathrm{CO}_{2}$ for up to $4 \mathrm{~h}$ at $37^{\circ} \mathrm{C}$. After the prescribed duration of hypoxia, the KCs were placed back in a regular incubator for $6 \mathrm{~h}$ for reoxygenation. The culture medium and KCs were collected for further analysis.

\section{TNF- $\alpha$ assay}

The concentration of TNF- $\alpha$ in the KC culture medium was assayed by using ELISA kit as per the manufacturer's specifications (Shanghai Senxiong Biotech, China).

\section{Measurement of ROS}

The ROS production by KCs was quantified as described previously, with minor modifications ${ }^{12}$. In brief, KCs were incubated with $100 \mu \mathrm{M}$ $2^{\prime}, 7^{\prime}$-dichlorfluorescein- diacetate (DCFH-DA) in the loading medium in $5 \% \mathrm{CO}_{2} / 95 \%$ air at $37^{\circ} \mathrm{C}$ for 30 min. Then, DCFH-DA was removed, and cells were rinsed with PBS. The fluorescence in each well was measured using a Galaxy Microplate Reader with an excitation wavelength of $485 \mathrm{~nm}$ and emission wavelength of $520 \mathrm{~nm}$ at $37^{\circ} \mathrm{C}$.

\section{Apoptosis analysis}

Apoptosis was assayed by Annexin-V/PI staining (BioVision Inc. USA). Annexin $\mathrm{V}$ staining can identify apoptosis at an earlier stage, and in combination with PI staining makes it possible to identify early apoptotic cells from dead cells. Briefly, treated or untreated KCs were collected, washed in cold PBS, incubated for $30 \mathrm{~min}$ at $4^{\circ} \mathrm{C}$ in the presence of $10 \mu \mathrm{l}$ Annexin V-FITC and $200 \mu \mathrm{l}$ binding buffer (all reagents provided by the manufacturer), and then mixed with $5 \mu \mathrm{l}$ propidium iodide and incubated for another $5 \mathrm{~min}$ at $4^{\circ} \mathrm{C}$. Then, $400 \mu \mathrm{l}$ binding buffer was added to each tube, and the cells were analyzed by flow cytometry. Annexin-V and PI were used to differentiate normal living cells (Annexin $\mathrm{V}^{-} / \mathrm{PI}$ ), mechanically injured cells (Annexin $\mathrm{V}^{-} / \mathrm{PI}^{+}$) and early apoptotic cells (Annexin $\mathrm{V}^{+} / \mathrm{PI}$ ) from late apoptotic cells (Annexin $\left.\mathrm{V}^{+} / \mathrm{PI}^{+}\right)$.

\section{Statistics}

The results were expressed as the mean \pm standard deviation. Statistical analysis was performed using one-way ANOVA. A probability level of $P<0.05$ was considered statistically significant.

\section{Results}

\section{TNF- $\alpha$ concentration in the culture medium}

The TNF- $\alpha$ concentration in the culture medium was $31.62 \pm 4.58 \mathrm{pg} / \mathrm{ml}$ of the control group and $418.33 \pm 17.5 \mathrm{pg} / \mathrm{ml}$ in lipid-pretreated group. As shown in Fig. 1, emulsified isoflurane preconditioning decreased the TNF- $\alpha$ concentration in the culture medium significantly $(193.17 \pm 7.65 \mathrm{pg} / \mathrm{ml}$ in the $0.1 \%$ EI group and $165.50 \pm 7.84 \mathrm{pg} / \mathrm{ml}$ in the $0.2 \%$ EI group versus $418.33 \pm 17.5 \mathrm{pg} / \mathrm{ml}$ in the lipid group, $\mathrm{P}<0.05$ ).

\section{ROS production in KCs}

A low level of fluorescence was present in the control group, while the intensity of DCF-labeled cells was markedly increased in the lipid group, indicating high ROS production. As shown in Fig. 2, emulsified isoflurane preconditioning attenuated the increase of fluorescent intensity relative to the lipid group. Treatment with either $0.1 \%$ or $0.2 \%$ emulsified isoflurane significantly inhibited the H/R-induced intracellular accumulation of ROS.

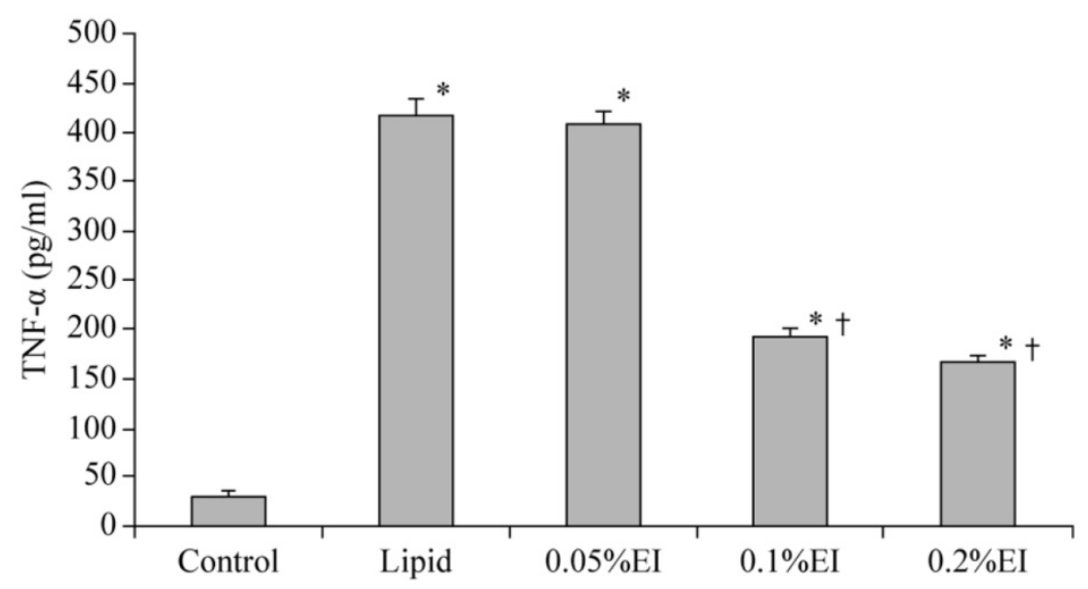

Fig. I. TNF- $\alpha$ concentration in the culture medium of KCs. The TNF- $\alpha$ concentration was significantly higher in the H/R group that in cells that had been preconditioned with $0.1 \%$ or $0.2 \%$ emulsified isoflurane. Data are expressed as the mean $\pm S D, n=10$. $* P<0.05$ compared with the control group; $\uparrow P<0.05$ compared with the lipid-treated $H / R$ group. 


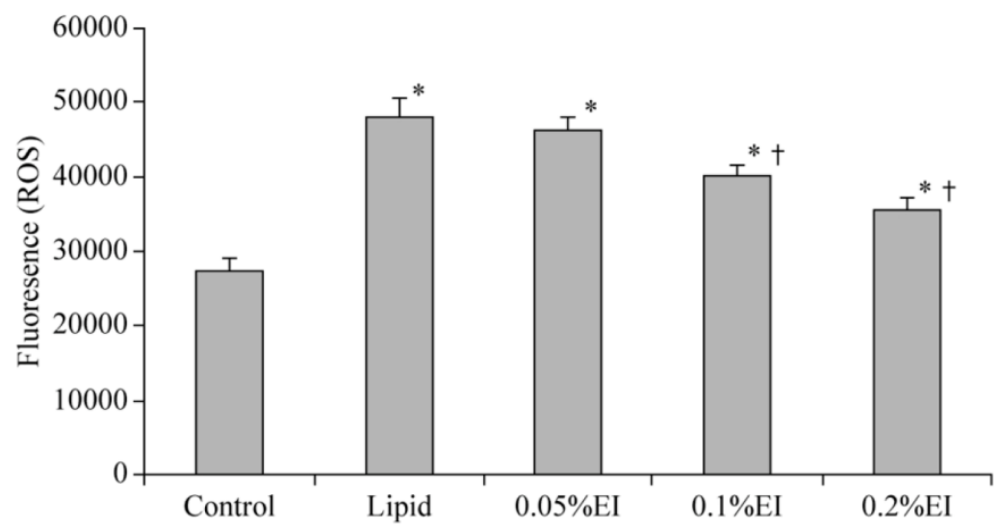

Fig. 2. Intracellular ROS levels in KCs. The intensity of DCF-labeling in the cells was markedly elevated in the H/R group and attenuated preconditioning with $0.1 \%$ or $0.2 \%$ emulsified isoflurane preconditioning. Data are expressed as the mean $\pm S D, n=10 * P<0.05$ compared with the control group; $\uparrow P<0.05$ compared with the lipid-treated $H / R$ group.
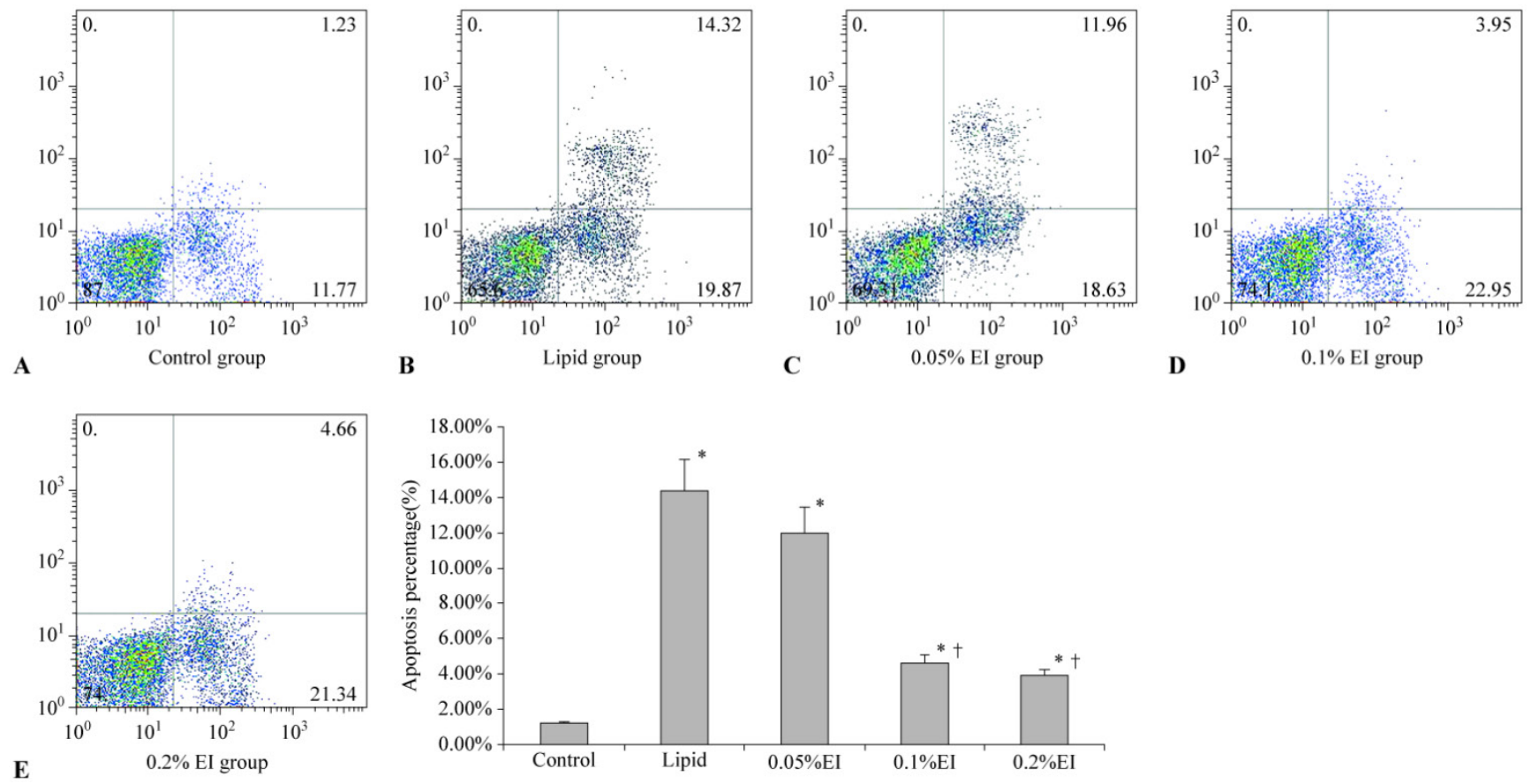

Fig. 3. Apoptosis rates in KCs. A: control group; B: lipid-treated $H / R$ group; C: $0.05 \%$ El-preconditioned $H / R$ group; $D$ : $0.1 \%$ El-preconditioned H/R group; E: $0.2 \%$ El preconditioned H/R group. Data are expressed as the mean $\pm S D, n=10 . * P<0.05$ compared with the control group; $\uparrow P<0.05$ compared with the lipid-preconditioned $H / R$ group.

\section{Flow cytometry analysis of cell apoptosis}

Cells in the control group were mainly located in the left lower quadrant and rarely observed in the right quadrant (Fig. 3A), with an apoptotic percentage of $1.17 \% \pm 0.10 \%$. The majority of cells in the lipid group were earlier apoptotic cells in the right lower quadrant and later apoptotic cells in the right upper quadrant (Fig. 3B). The $0.1 \%$ EI group and $0.2 \%$ EI groups contained fewer apoptotic cells (Fig. 3D and $3 \mathrm{E})$, similar to the control group. The distribution of cells in the $0.05 \%$ IP group was similar to that in the lipid group (Fig. 3C). The percentage of apoptotic KCs was significantly lower in the $0.1 \%$ and $0.2 \%$ EI groups than in the lipid group $(4.59 \% \pm 0.42 \%$ and $4.07 \% \pm 0.27 \%$ versus $14.41 \% \pm 1.89 \%, \mathrm{P}<0.05$ ) (Fig. $3 \mathrm{~F}$ ). The percentage of apoptotic KCs in the $0.05 \%$ EI group was $12.05 \% \pm 1.52 \%$. There was no significant difference between the lipid group and $0.05 \%$ EI group $(\mathrm{P}>0.05)$. 


\section{Discussion}

In the present study, we investigated the effect of emulsified isoflurane preconditioning on hypoxia/reoxygenation-induced injury to primarily cultured KCs. We found that emulsified isoflurane protected isolated rat KCs against hypoxia/reoxygenation-induced injury, as evidenced by decreased ROS and TNF-a production and less apoptosis of KCs.

Emulsified isoflurane has been the subject of recent research because it was found to eliminate the need for specific ventilatory circuits, provide rapid anesthetic induction and recovery, has remarkable hemodynamic stability ${ }^{14}$ and low environmental pollution and tissue toxicity ${ }^{15}$. Preconditioning with emulsified isoflurane has been found to attenuate oxidative stress and prevent I/R injury in the rat heart ${ }^{16}$. Rao et $\mathrm{al}^{17}$ demonstrated that emulsified isoflurane protected the myocardium against I/ $R$ injury similar to inhaled isoflurane.

KCs are considered to play a major role in hepatic I/R injury. During the initial stages of reperfusion, KCs are activated and underwent morphologic changes, causing them to protrude into the sinusoids, which contributes to the reduction of blood flow within the sinusoidal lumen ${ }^{18}$. Activated KCs release large amounts of not only TNF-a and IL-1 but also prostaglandin E and ROS'19.

There is evidence suggesting that hepatocyte injury occurs during the relatively hypoxic early phase of IRI. ROS release is one of the earliest and most important events in tissue injury after the reperfusion of ischemic organs ${ }^{19}$, and it is a major contributor to hepatocyte death during reperfusion. ROS can activate redox-sensitive transcription factors, thereby activating proinflammatory genes and increasing the hepatic damage. Furthermore, ROS may activate calcium-dependent proteases (calpains) and mediate several intracellular processes that result in necrotic or apoptotic cell death. ROS can therefore be considered signaling molecules, which trigger several pivotal mechanisms of reperfusion injury. Consequently, antioxidant strategies appear to be promising for the prevention of hepatic reperfusion injury ${ }^{20}$.

Antioxidants and inhibitors of ROS generation have been shown to abrogate cell death during hypoxia in a human hepatoma cell line. Bhogal et $\mathrm{al}^{21}$ found that the decrease in ROS production observed in hepatocytes isolated from the tissue of patients with biliary diseases was accompanied by a concomitant decrease in apoptosis and necrosis, confirming the association between ROS and apoptotic/ necrotic cell death. The reduction of endogenous ROS levels in human hepatocytes treated with various inhibitors led to a significant decrease in hepatocyte apoptosis and necrosis. These data provide clear evidence that endogenous ROS drives human hepatocyte apoptosis and necrosis during $H / R$.

The pharmacological inactivation of KCs has been reported to suppress hepatic I/R injury. Mosher et $\mathrm{al}^{22}$ reported that the inhibition of KC activity with gadolinium chloride provided a potential means of preventing hepatocellular injury caused by reperfusion of the ischemic liver. Carbon monoxide (CO) preconditioning reduced peak alanine aminotransferase levels and hepatic necrosis and efficiently inhibited TNF- $\alpha$ and IL-6 up-regulation in CD68+ ${ }^{+}$KCs fraction. In addition, $\mathrm{CO}$ preconditioning inhibited LPS-induced inflammatory responses in primary cultures of rat KCs. Tomiyama et $\mathrm{al}^{23}$ reported that $\mathrm{CO}$ ameliorated hepatic I/R injury by down-regulating graft $\mathrm{KCs}$ in the early post-reperfusion period. Lee et $\mathrm{al}^{24}$ found that preconditioning with $\mathrm{CO}$ could inhibit ROS generation and TNF-alpha production in vitro and reduce the expression of pro-apoptotic Bax mRNA, cleaved caspase-3 and PARP. In our study, ROS generation was obviously induced by hypoxia and reoxygenation, and this induction was inhibited emulsified isoflurane preconditioning. The reduction in endogenous ROS release from isolated rat $\mathrm{KCs}$ led to significantly decreased KC apoptosis.

Peng et al ${ }^{25}$ demonstrated that Fas/FasL induced $\mathrm{KC}$ apoptosis in an experimental pancreatitis model and showed that Fas/Fal may have a protective effect by reducing the number of activated $\mathrm{KCs}$ and thus reducing overall cytokine production in the liver. However, Tello et $\mathrm{al}^{26}$ suggested that $\mathrm{KC}$ apoptosis could increase the TNF-a concentration in the culture medium, most likely due to cell death rather than the active release or synthesis of TNF-a from KCs. Our results are consistent with their work, demonstrating that emulsified isoflurane preconditioning inhibited KC apoptosis and decreased the TNF- $a$ concentration of the surrounding culture medium.

Taken together, our data show that emulsified isoflurane preconditioning has a protective effect against hypoxia/reoxygenation-induced $\mathrm{KC}$ injury, as indicated by the decreased ROS and TNF- $\alpha$ production. This protective effect may be related to the reduction of $\mathrm{KC}$ apoptosis. Emulsified isoflurane may be useful in alleviating ischemia reperfusion injury caused by hepatic surgery, transplantation or hemorrhagic shock.

\section{Acknowledgements}

This work was supported by a grant from the Innovation Program of Shanghai Municipal Educa- 
tion Committee. (Grant No. 12ZZ081).

\section{Conflict of Interest}

The authors have declared that no conflict of interest exists.

\section{References}

1. Murry CE, Jennings RB, Reimer KA. Preconditioning with ischemia: a delay of lethal cell injury in ischemic myocardium. Circulation 1986; 74: 1124-36.

2. Kersten JR, Schmeling TJ, Pagel PS, Gross GJ, Warltier DC. Isoflurane mimics ischemic preconditioning via activation of K (ATP) channels: reduction of myocardial infarct size with an acute memory phase. Anesthesiology 1997; 87: 361-70.

3. Sato T, Asanuma Y, Masaki Y, et al. Changes in tumor necrosis factor-alpha and interleukin-1 beta production following liver surgery on cirrhotic patients. Hepatogastroenterology 1996; 43: 1148-53.

4. Lichtman SN, Lemasters JJ. Role of cytokines and cytokine-producing cells in reperfusion injury to the liver. Semin Liver Dis 1999; 19: 171-87.

5. Bremer C, Bradford BU, Hunt KJ, et al. Role of Kupffer cells in the pathogenesis of hepatic reperfusion injury. Am J Physiol 1994; 267: G630-6.

6. Lv X, Wang ZM, Huang SD, Song SH, Wu FX, Yu WF. Emulsified isoflurane preconditioning reduces lung injury induced by hepatic ischemia/reperfusion in rats. Int J Med Sci 2011; 8: 353-61.

7. Yang XL, Ma HX, Yang ZB, et al. Comparison of minimum alveolar concentration between intravenous isoflurane lipid emulsion and inhaled isoflurane in dogs. Anesthesiology 2006; 104: 482-7.

8. Valatas V, Xidakis C, Roumpaki H, Kolios G, Kouroumalis EA. Isolation of rat Kupffer cells: a combined methodology for highly purified primary cultures. Cell Biol Int 2003; 27: 67-73.

9. Titos E, Claria J, Planaguma A, et al. Inhibition of 5-lipoxygenase induces cell growth arrest and apoptosis in rat Kupffer cells: implications for liver fibrosis. Faseb J 2003; 17: 1745-7.

10. Widmann JJ, Cotran RS, Fahimi HD. Mononuclear phagocytes (Kupffer cells) and endothelial cells. Identification of two functional cell types in rat liver sinusoids by endogenous peroxidase activity. J Cell Biol 1972; 52: $159-70$.

11. Koivisto T, Mishin VM, Mak KM, Cohen PA, Lieber CS. Induction of cytochrome P-4502E1 by ethanol in rat Kupffer cells. Alcohol Clin Exp Res 1996; 20: 207-12.

12. Wong H, Joseph JA. Quantifying cellular oxidative stress by dichlorofluorescein assay using microplate reader. Free Radic Biol Med 1999; 27: 612-6.

13. Mathias LA, Piccinini Filho L, Rittes JC, et al. Intravenous isoflurane in lipid emulsion promotes cardiovascular and respiratory stability. Experimental model. Rev Bras Anestesiol 2004; 54: 656-62.

14. Hu ZY, Luo NF, Liu J. The protective effects of emulsified isoflurane on myocardial ischemia and reperfusion injury in rats. Can J Anaesth 2009; 56: $115-25$.

15. Lucchinetti E. Schaub MC. Zaugg M. Emulsified intravenous versus evaporated inhaled isoflurane for heart protection: old wine in a new bottle or true innovation? Anesth Analg 2008; 106: 1346-9.

16. Rao Y, Wang Y, Zhang W, Liu J. Emulsified isoflurane produces cardiac protection after ischemia reperfusion injury in rabbits. Anesth Analg. 2008 May;106(5):1353-9.

17. Shiratori $Y$, Kiriyama H, Fukushi $Y$, et al. Modulation of ischemia reperfusion induced hepatic injury by Kupffer cells. Dig Dis Sci 1994; 39: 1265-72.

18. Cutrn JC, Perrelli MG, Cavalieri B, Peralta C, Rosell Catafau J, Poli G. Microvascular dysfunction induced by reperfusion injury and protective effect of ischemic preconditioning. Free Radic Biol Med 2002; 33: 1200-8.

19. Hool LC. Reactive oxygen species in cardiac signalling: from mitochondria to plasma membrane ion channels. Clin Exp Pharmacol Physiol 2006; 33: 146-51.

20. Schauer RJ, Gerbes AL, Vonier D, et al. Glutathione protects the rat liver against reperfusion injury after prolonged warm ischemia. Ann Surg 2004; 239: 220-31.

21. Bhogal RH, Curbishley SM, Weston CJ, Adams DH, Afford SC. Reactive oxygen species mediate human hepatocyte injury during hypoxia/reoxygenation. Liver Transpl 2010; 16: 1303-13.

22. Mosher B, Dean R, Harkema J, Remick D, Palma J, Crockett E. Inhibition of Kupffer cells reduced CXC chemokine production and liver injury. J Surg Res 2001; 99: 201-10.
23. Tomiyama K, Ikeda A, Ueki S, et al. Inhibition of Kupffer cell-mediated early proinflammatory response with carbon monoxide in transplant-induced hepatic ischemia/reperfusion injury in rats. Hepatology 2008; 48: 1608-20.

24. Lee LY, Kaizu T, Toyokawa H, et al. Carbon monoxide induces hypothermia tolerance in kupffer cells and attenuates liver ischemia/reperfusion injury in rats. Liver Transpl 2011; 17: 1457-66.

25. Peng Y, Gallagher SF, Haines K, Baksh K, Murr MM. Nuclear factor-kappaB mediates Kupffer cell apoptosis through transcriptional activation of Fas/FasL. J Surg Res 2006; 130: 58-65.

26. Tello K, Christiansen H, Gurleyen H, et al. Irradiation leads to apoptosis of Kupffer cells by a Hsp27-dependant pathway followed by release of TNF-alpha. Radiat Environ Biophys 2008; 47: 389-97. 